\title{
Hidden Basal Cell Carcinoma in the Intergluteal Crease
}

\author{
Lauren Schwartzberg, OMS-IV; Navin Arora, DO
}

Basal cell carcinoma (BCC) is the most common cancer and often is found in sun-exposed areas, particularly the head and neck. However, BCCs also can arise in unexpected locations. Intergluteal crease BCC is a rare finding and often can be overlooked. When promptly identified, prognosis is good. Being educated on the existence of BCC in this sensitive area can aid proper diagnosis. This sensitive area should be included in a thorough skin examination to avoid missing this treatable cancer. We report the case of an 83-year-old woman with a BCC hidden in the intergluteal crease.

Cutis. 2021;107:95-96.

\section{Practice Gap}

Basal cell carcinoma (BCC) is the most common cancer, and its incidence is on the rise. ${ }^{1}$ The risk of this skin cancer is increased when there is a history of squamous cell carcinoma (SCC) or BCC. ${ }^{2}$ Basal cell carcinoma often is found in sun-exposed areas, most commonly due to a history of intense sunburn. ${ }^{3}$ Other risk factors include male gender and increased age. ${ }^{4}$

Eighty percent to $85 \%$ of BCCs present on the head and neck ${ }^{5}$; however, BCC also can occur in unusual locations. When BCC presents in areas such as the perianal region, it is found to be larger than when found in more common areas, ${ }^{6}$ likely because neoplasms in this sensitive area often are overlooked. Literature on BCC of the intergluteal crease is limited. ${ }^{7}$ Being educated on the existence of BCC in this sensitive area can aid proper diagnosis.

\section{The Technique and Case}

An 83-year-old woman presented to the dermatology clinic for a suspicious lesion in the intergluteal crease that was tender to palpation with drainage. She first noticed this lesion and reported it to her primary care physician at a visit 6 months prior. The primary care physician did not pursue investigation of the lesion. One month later, the patient was seen by a gastroenterologist for the lesion and was referred to dermatology. The patient's medical history included SCC and BCC on the face, both treated successfully with Mohs micrographic surgery.

Physical examination revealed a $2.6 \times 1.1-\mathrm{cm}$, erythematous, nodular plaque in the coccygeal area of the intergluteal crease (Figure 1). A shave biopsy disclosed BCC, nodular type, ulcerated. Microscopically, there were nodular aggregates of basaloid cells with hyperchromatic nuclei and peripheral palisading, separated from mucinous stromal surroundings by artefactual clefts.

The initial differential diagnosis for this patient's lesion included an ulcer or SCC. Basal cell carcinoma was not suspected due to the location and appearance of the lesion. The patient was successfully treated with Mohs micrographic surgery.

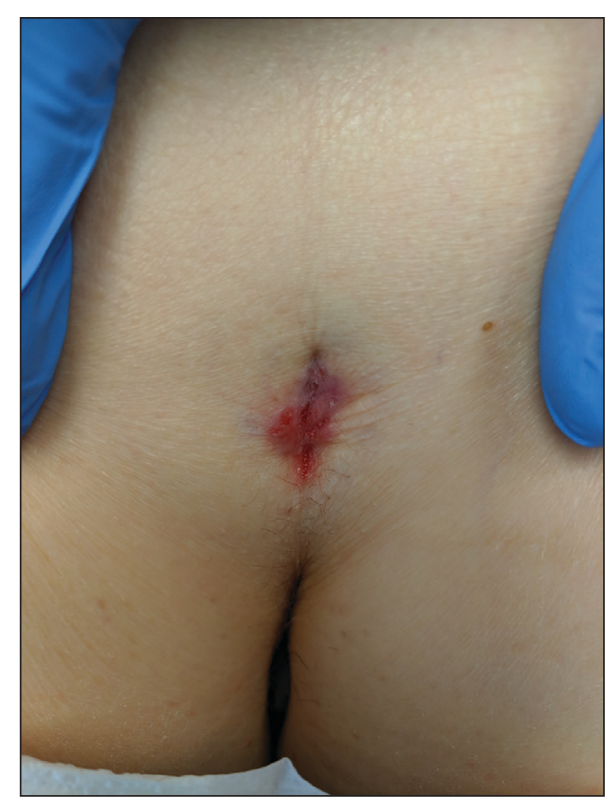

FIGURE 1. Basal cell carcinoma in the coccygeal region.

Ms. Schwartzberg is from New York Institute of Technology College of Osteopathic Medicine, Old Westbury. Dr. Arora is from the Ronald O. Perelman Department of Dermatology, New York University Langone Health, New York, and Borealis Dermatology, Garden City, New York. The authors report no conflict of interest. 


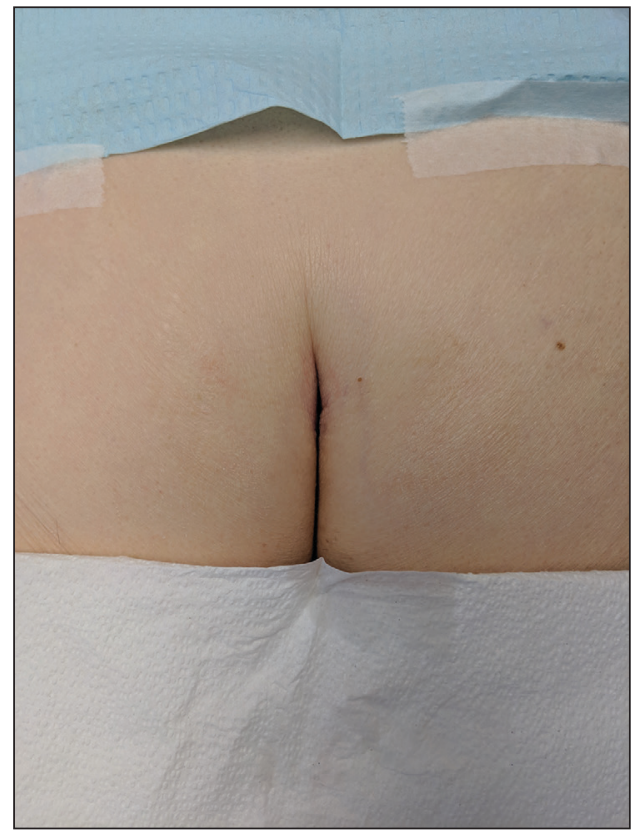

FIGURE 2. Hidden coccygeal lesion.

\section{Practical Implications}

Without thorough examination, this cancerous lesion would not have been seen (Figure 2). Therefore, it is important to practice thorough physical examination skills to avoid missing these cancers, particularly when examining a patient with a history of SCC or BCC. Furthermore, biopsy is recommended for suspicious lesions to rule out BCC.

Be careful not to get caught up in epidemiological or demographic considerations when making a diagnosis of this kind or when assessing the severity of a lesion. This patient, for instance, was female, which makes her less likely to present with $\mathrm{BCC}{ }^{8}$ Moreover, the cancer presented in a highly unlikely location for BCC, where there had not been significant sunburn. ${ }^{9}$ Patients and physicians should be educated about the incidence of BCC in unexpected areas; without a second and close look, this BCC could have been missed.

\section{Final Thoughts}

The literature continuously demonstrates the rarity of $\mathrm{BCC}$ in the intergluteal crease. ${ }^{10}$ However, when perianal $\mathrm{BCC}$ is properly identified and treated with local excision, prognosis is good. ${ }^{11}$ Basal cell carcinoma has been seen to arise in other sensitive locations; vulvar, nipple, and scrotal BCC neoplasms are among the uncommon locations where BCC has appeared. ${ }^{12}$ These areas are frequentlyand easily-ignored. A total-body skin examination should be performed to ensure that these insidious-onset carcinomas are not overlooked to protect patients from the adverse consequences of untreated cancer. ${ }^{13}$

\section{REFERENCES}

1. Roewert-Huber J, Lange-Asschenfeldt B, Stockfleth E, et al. Epidemiology and aetiology of basal cell carcinoma. $\mathrm{Br} J$ Dermatol. 2007;157(suppl 2):47-51.

2. Rogers HW, Weinstock MA, Feldman SR, et al. Incidence estimate of nonmelanoma skin cancer (keratinocyte carcinomas) in the US population, 2012. JAMA Dermatol. 2015;151:1081-1086.

3. Zanetti R, Rosso S, Martinez C, et al. Comparison of risk patterns in carcinoma and melanoma of the skin in men: a multi-centre casecase-control study. Br J Cancer. 2006;94:743-751.

4. Marzuka AG, Book SE. Basal cell carcinoma: pathogenesis, epidemiology, clinical features, diagnosis, histopathology, and management. Yale J Biol Med. 2015;88:167-179.

5. Lorenzini M, Gatti S, Giannitrapani A. Giant basal cell carcinoma of the thoracic wall: a case report and review of the literature. $\mathrm{Br}$ J Plast Surg. 2005;58:1007-1010.

6. Lee HS, Kim SK. Basal cell carcinoma presenting as a perianal ulcer and treated with radiotherapy. Ann Dermatol. 2015;27:212-214.

7. Salih AM, Kakamad FH, Rauf GM. Basal cell carcinoma mimicking pilonidal sinus: a case report with literature review. Int J Surg Case Rep. 2016;28:121-123.

8. Scrivener Y, Grosshans E, Cribier B. Variations of basal cell carcinomas according to gender, age, location and histopathological subtype. Br J Dermatol. 2002;147:41-47.

9. Park J, Cho Y-S, Song K-H, et al. Basal cell carcinoma on the pubic area: report of a case and review of 19 Korean cases of BCC from nonsun-exposed areas. Ann Dermatol. 2011;23:405-408.

10. Damin DC, Rosito MA, Gus P, et al. Perianal basal cell carcinoma. J Cutan Med Surg. 2002;6:26-28.

11. Paterson CA, Young-Fadok TM, Dozois RR. Basal cell carcinoma of the perianal region: 20-year experience. Dis Colon Rectum. 1999;42:1200-1202.

12. Mulvany NJ, Rayoo M, Allen DG. Basal cell carcinoma of the vulva: a case series. Pathology. 2012;44:528-533.

13. Leonard D, Beddy D, Dozois EJ. Neoplasms of anal canal and perianal skin. Clin Colon Rectal Surg. 2011;24:54-63. 